\title{
115
}

\section{Cross - National Decision Making in a Group Support Systems Environment}

\author{
Nasrin Rahmati (Mrs.) \\ PhD Candidate \\ School of Information Systems \\ Faculty of Business and Management \\ University of South Australia \\ Email9510372M@FBM.pcmail.levels.unisa.edu.au
}

\begin{abstract}
Group Support Systems were designed and developed with the aim of supporting groups in their decision making efforts. According to small group theories the important variables in groupwork were group size, task and environment (eg, McGrath, 1984). Psychologists believe that decision making entails two major phases: perception of the given situation, and selection of an option on the basis of what is perceived (Yates and Lee, 1996). The importance of the decision maker's perception in the decision making process suggests that in addition to age, sex, educational background and job experience of the decision maker his/her value system is also very important to be examined in GSS studies. The present study is an exploratory study using controlled laboratory experiments to examine the impact of the culture (value system) on decision making process in a Group Support Systems environment.
\end{abstract}

KEYWORDS: Group Support Systems, National Culture

Human-Computer Interaction: INTERACT'97 S. Howard, J. Hammond \& G. Lindgaard (editors)

Published by Chapman \& Hall OIFIP 1997 